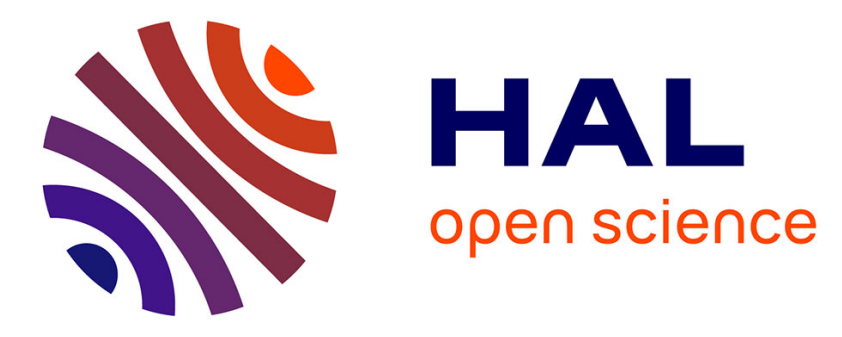

\title{
Unusual structure, bonding and properties in a californium borate
}

\author{
Matthew J. Polinski, Edward B. Garner, Rémi Maurice, Nora Planas, Jared \\ T. Stritzinger, T. Gannon Parker, Justin N. Cross, Thomas D. Green, Evgeny \\ V. Alekseev, Shelley M. van Cleve, et al.
}

\section{To cite this version:}

Matthew J. Polinski, Edward B. Garner, Rémi Maurice, Nora Planas, Jared T. Stritzinger, et al.. Unusual structure, bonding and properties in a californium borate. Nature Chemistry, 2014, 6, pp.387392. 10.1038/nchem.1896 . in2p3-00966875

\section{HAL Id: in2p3-00966875 https://hal.in2p3.fr/in2p3-00966875}

Submitted on 27 Mar 2014

HAL is a multi-disciplinary open access archive for the deposit and dissemination of scientific research documents, whether they are published or not. The documents may come from teaching and research institutions in France or abroad, or from public or private research centers.
L'archive ouverte pluridisciplinaire HAL, est destinée au dépôt et à la diffusion de documents scientifiques de niveau recherche, publiés ou non, émanant des établissements d'enseignement et de recherche français ou étrangers, des laboratoires publics ou privés. 


\title{
Unusual Structure, Bonding, and Properties in a Californium Borate
}

Matthew J. Polinski, ${ }^{1}$ Edward B. Garner, III, ${ }^{2}$ Rémi Maurice, ${ }^{3,4}$ Nora Planas, ${ }^{3}$ Jared T. Stritzinger, ${ }^{1}$ T. Gannon Parker, ${ }^{1}$ Justin N. Cross, ${ }^{1}$ Thomas D. Green, ${ }^{1}$ Evgeny V. Alekseev, ${ }^{5}$ Shelley M. Van Cleve, ${ }^{6}$ Wulf Depmeier, ${ }^{7}$ Laura Gagliardi, ${ }^{3}$ Michael Shatruk, ${ }^{1}$ Kenneth L. Knappenberger, ${ }^{1}$ Guokui Liu, ${ }^{8}$ S. Skanthakumar, ${ }^{8}$ Lynda Soderholm, ${ }^{8}$ David A. Dixon, ${ }^{2}$ Thomas E. Albrecht-Schmitt ${ }^{1, *}$

\author{
Affiliations: \\ ${ }^{1}$ Department of Chemistry and Biochemistry, Florida State University, Tallahassee, Florida \\ 32306 \\ ${ }^{2}$ Department of Chemistry, The University of Alabama, Shelby Hall, Tuscaloosa AL 35487 \\ ${ }^{3}$ Department of Chemistry, Supercomputing Institute, and Chemical Theory Center, University \\ of Minnesota, 207 Pleasant Street SE, Minneapolis, Minnesota 55455 \\ ${ }^{4}$ SUBATECH, UMR CNRS 6457, IN2P3/EMN Nantes/Université de Nantes, 4 rue Alfred \\ Kastler, BP20722, 44307 Nantes Cédex 3, France \\ ${ }^{5}$ Institute for Energy and Climate Research (IEK-6), Forschungszentrum Jülich GmbH, 52428 \\ Jülich, Germany and Institut für Kristallographie, RWTH Aachen University, 52066 Aachen, \\ Germany \\ ${ }^{6}$ Nuclear Materials Processing Group, Oak Ridge National Laboratory, One Bethel Valley Rd, \\ Oak Ridge, Tennessee 37830 \\ ${ }^{7}$ Institut für Geowissenschaften, Universität Kiel, 24118 Kiel, Germany \\ ${ }^{8}$ Chemical Sciences and Engineering Division, Argonne National Laboratory, Argonne, IL \\ 60439 \\ *albrecht-schmitt@chem.fsu.edu
}

\begin{abstract}
The participation of the valence orbitals of actinides in bonding has been debated for decades. Recent experimental and computational investigations have demonstrated the involvement of $6 p, 6 d$, and/or $5 f$ orbitals in bonding. However, structural and spectroscopic data, as well as theory, indicate a decrease in covalency across the actinide series, and the evidence points to highly ionic, lanthanide-like bonding for late actinides. In this work, we show that chemical differentiation between californium and lanthanides can be achieved by using ligands that are both highly polarizable and that substantially rearrange upon complexation. A ligand that suits both of the above desired properties is polyborate. We demonstrate that the $5 f, 6 d$, and $7 p$ orbitals are all involved in bonding in a $\mathrm{Cf}(\mathrm{III})$ borate, and that large crystal field effects are present. Synthetic, structural, and spectroscopic data are complemented by quantum mechanical calculations to support these observations.
\end{abstract}


Californium is the heaviest element currently on earth, and is the last member of the actinide series that has an isotope long-lived enough for work to be carried out in a standard radiologic facility. Synthetic studies on californium chemistry have typically been restricted to microgram scales, and detailed measurements that correlate structure and physico-chemical properties are lacking. The limited examples of californium compounds can be ascribed to variety of factors that include the low isotopic availability of this element, the short half-life of the longest-lived available isotope $\left({ }^{249} \mathrm{Cf}=351 \mathrm{yr}\right)$, and the extreme $\alpha$ and $\gamma$ emissions (6.194 $\mathrm{MeV}$ and $0.388 \mathrm{MeV}$, respectively).

Only five single crystal structures have been determined: $\mathrm{Cf}\left(\mathrm{IO}_{3}\right)_{3},{ }^{1}$ the orthorhombic and hexagonal forms of $\mathrm{CfCl}_{3},{ }^{2} \mathrm{Cf}(\mathrm{Cp})_{3},{ }^{3}$ and $\left[\mathrm{Cf}\left(\mathrm{H}_{2} \mathrm{O}\right)_{9}\right]\left[\mathrm{CF}_{3} \mathrm{SO}_{3}\right]_{3} .{ }^{4}$ These compounds have isotypic lanthanide analogs. In the case of the $\left[\mathrm{M}\left(\mathrm{H}_{2} \mathrm{O}\right)_{9}\right]\left[\mathrm{CF}_{3} \mathrm{SO}_{3}\right]_{3}\left(\mathrm{M}=\mathrm{Ln}^{3+}\right.$ or $\left.\mathrm{An}^{3+}\right)$, the bonding is purely ionic, meaning that the valence $5 f$ orbitals of the actinide cations are nonbonding, much like the $4 f$ orbitals for lanthanides ${ }^{5-7}$ However, there are numerous examples, based on structural, spectroscopic evidence, and electronic structure calculations, that indicate the involvement of the $6 p, 6 d$, and/or $5 f$ orbitals in bonding with actinides, yielding bonds to ligands that are partially covalent. ${ }^{8-10}$ An additional impediment in finding covalent bonding with trivalent actinides is that the degree of covalency decreases with the lowering of the oxidation state, and therefore the effects of covalency with trivalent actinides are expected to be quite small. ${ }^{8,9}$ Actinides beyond plutonium are typically trivalent and their structural chemistry, much like that of isoelectronic lanthanides, is thought to be determined solely by their ionic radii.

We recently demonstrated that highly polarizable ligands, in this case polyborates, are able to form covalent bonds with the trivalent actinides Pu(III), Am(III), and $\mathrm{Cm}$ (III), and that this covalency is associated with the formation of structures that are not paralleled by lanthanides. Moreover, these neighboring actinides do not form an isotypic series with each other; each actinide displays unique chemistry. ${ }^{10}$ To understand how bonding changes across the actinide series, we investigated the synthetic, structural, spectroscopic, and quantum chemical properties of a $\mathrm{Cf}(\mathrm{III})$ borate and found many unanticipated results that are detailed in this report. 


\section{Results and Discussion}

The reaction of ${ }^{249} \mathrm{CfCl}_{3}$ with molten boric acid yields pale green microcrystals of $\mathrm{Cf}\left[\mathrm{B}_{6} \mathrm{O}_{8}(\mathrm{OH})_{5}\right]$ as the only isolated product. This contrasts sharply with $\mathrm{Pu}(\mathrm{III}), \mathrm{Am}(\mathrm{III})$, and $\mathrm{Cm}$ (III) that yield $\mathrm{Pu}\left[\mathrm{B}_{4} \mathrm{O}_{6}(\mathrm{OH})_{2} \mathrm{Cl}\right], \mathrm{Pu}_{2}\left[\mathrm{~B}_{13} \mathrm{O}_{19}(\mathrm{OH})_{5} \mathrm{Cl}_{2}\left(\mathrm{H}_{2} \mathrm{O}\right)_{3}\right], A m\left[\mathrm{~B}_{9} \mathrm{O}_{13}(\mathrm{OH})_{4}\right] \cdot \mathrm{H}_{2} \mathrm{O}$, and $\mathrm{Cm}_{2}\left[\mathrm{~B}_{14} \mathrm{O}_{20}(\mathrm{OH})_{7}\left(\mathrm{H}_{2} \mathrm{O}\right)_{2} \mathrm{Cl}\right]$, respectively. ${ }^{10}$ These four lighter actinide compounds share many similar structural features that include polyborate layers in which the actinides reside. Bridging by borate anions creates three-dimensional framework structures. The $\mathrm{Pu}(\mathrm{III}), \mathrm{Am}(\mathrm{III})$, and $\mathrm{Cm}$ (III) metal ions are either nine- or ten-coordinate and adopt highly anisotropic coordination environments with either a hula-hoop ${ }^{11}$ or capped triangular cupola ${ }^{12}$ geometries.

The structure of $\mathrm{Cf}\left[\mathrm{B}_{6} \mathrm{O}_{8}(\mathrm{OH})_{5}\right]$, reported in this work, bears no similarities with the previously reported trivalent actinide borates. First, the polyborate scaffolding forms onedimensional chains fashioned from a new fundamental building unit for $f$-elements as shown in Figure 1a. This unit consists of four corner-shared $\mathrm{BO}_{4}$ tetrahedra and two $\mathrm{BO}_{3}$ triangles. Three chains wrap around each $\mathrm{Cf}(\mathrm{III})$ center creating an eight-coordinate square antiprismatic coordination environment as shown in Figure 1b (see also Supplementary Fig. 3). Note that although the eight $\mathrm{Cf}-\mathrm{O}$ distances are quite similar, the geometry is far from being a perfect square antiprism (large angular distortions are observed in this first coordination sphere). The bridging of the chains by the $\mathrm{Cf}(\mathrm{III})$ centers creates sheets and the overall structure is layered (Figure 1c). All earlier members of the actinides series contain polyborate layers that are linked together into three-dimensional frameworks.

The $\mathrm{Cf}(\mathrm{III})$ ion resides on a twofold site (exhibiting $C_{2}$ symmetry), and the $\mathrm{Cf}-\mathrm{O}$ bond distances range from $2.411(5)$ to $2.463(5) \AA$. Thus, the smaller-sized Cf(III) cation yields both a lower coordination number and a more isotropic coordination environment than was previouly found with lighter actinide borates. Furthermore, while lanthanide borates containing smaller $\mathrm{Ln}(\mathrm{III})$ cations $(\mathrm{Ln}=\mathrm{Gd}-\mathrm{Lu})$ also form hexaborates, the polyborate forms sheets instead of chains, and the $\operatorname{Ln}(\mathrm{III})$ cations are nine-coordinate tricapped trigonal prisms. ${ }^{13}$ Therefore, the reported $\mathrm{Cf}(\mathrm{III})$ borate structure was not predictable from the previously reported structures involving any other $f$-element.

Magnetic susceptibility data were collected on a polycrystalline sample of $\mathrm{Cf}\left[\mathrm{B}_{6} \mathrm{O}_{8}(\mathrm{OH})_{5}\right]$ under an applied field of $0.1 \mathrm{~T}$. No evidence of long-range ordering was 
observed in the temperature range of 1.8-380 K (Figure 2; see also Supplementary Fig. 4). The data are fit over the entire temperature range with a modified Curie-Weiss law $\chi=\mathrm{C} /(\mathrm{T}-\theta)+\chi_{0}$, where $\mathrm{C}$ is the Curie constant from which the effective moment $\left(\mu_{\mathrm{eff}}\right)$ is obtained, $\theta$ is the Weiss constant (a term meant to account for short-range magnetic correlations or the influence of lowlying crystal-field states), and $\chi_{0}$ represents the temperature-independent paramagnetism. The best fit, shown as a solid line through the data in Figure 2, yields values of $\mu_{\mathrm{eff}}=6.7(4) \mu_{\mathrm{B}}, \theta=$ $0.5(2) \mathrm{K}$, and $\chi_{0}=4.44(4) \times 10^{-2} \mathrm{emu} / \mathrm{mol}$. The overall goodness-of-fit, together with the small Weiss constant, confirms that there are no significant interactions between $\mathrm{Cf}$ magnetic moments, a result consistent with expectations based on structural information. The shortest Cf... Cf distance is $4.625 \AA$, too long for direct interactions, whereas a magnetic superexchange pathway would involve an interaction through a bridging borate anion, which is not expected to result in a significant effective coupling. Within the single-ion regime, the fitted effective moment, $\mu_{\mathrm{eff}}$, is significantly smaller than the free-ion expectation value of $10.65 \mu_{\mathrm{B}}$, determined assuming a Hund's rule ground term $\left({ }^{6} \mathrm{H}_{15 / 2}\right)$ obtained from a $5 f^{9}$ configuration with RussellSaunders coupling. Other studies dealing with U(III) suggest that a significant degree of covalency can reduce the observed magnetic moment. ${ }^{14}$ Lacking magnetic studies on Cf(III), a comparison with published studies on $\mathrm{Dy}(\mathrm{III})$, the $4 f^{9}$ congener of $\mathrm{Cf}(\mathrm{III})$, reveals effective moments generally consistent with the full free-ion values, with reports of slightly decreased moments attributed to crystal-field effects. ${ }^{15,16}$ In these cases, the crystal field effects play only a minor role in the moment reduction. ${ }^{15,16}$ Thus, we postulate that significant covalency between the $\mathrm{Cf}(\mathrm{III})$ ion and the borate network may be responsible for the relatively low observed magnetic moment.

The electronic spectroscopy of $\mathrm{Cf}\left[\mathrm{B}_{6} \mathrm{O}_{8}(\mathrm{OH})_{5}\right]$ is rich, and the assigned solid-state absorption spectrum taken from a cluster of crystals is shown in Figure 3. ${ }^{17}$ The $f-f$ transitions shown are broader than are typically found even at $79 \mathrm{~K}$ and show features attributed to vibronic coupling. When a sample of $\mathrm{Cf}\left[\mathrm{B}_{6} \mathrm{O}_{8}(\mathrm{OH})_{5}\right]$ is irradiated with 365 or $420 \mathrm{~nm}$ light, emission occurs in the green centered at $525 \mathrm{~nm}$ (Figure 4). Much weaker luminescence is found in the NIR at $1020 \mathrm{~nm}$ when $546 \mathrm{~nm}$ light is used. The emission at $525 \mathrm{~nm}$ is very broad and has the signature of strong vibronic coupling. Vibronic coupling has been found in the electronic spectra of several lanthanide compounds, ${ }^{18,19}$ and is therefore not necessarily indicative of coupling 
between ligand vibrations and metal orbitals that one finds with transition metals. However, the effects of vibronic coupling in lanthanide compounds are very small and typically only spread the original electronic transition out by a few nanometers. ${ }^{18,19}$ Although such coupling is known to be larger in actinide compounds, the electron-phonon coupling strength is typically only two or three times larger than found in lanthanides. ${ }^{18}$ In contrast, at $79 \mathrm{~K}$ the $\mathrm{J}=5 / 2$ excited state transition to the $\mathbf{J}=15 / 2$ ground state is expected to be a few nanometers wide at most, but instead it is approximately $140 \mathrm{~nm}$ wide. The broadening observed is much more similar to that observed in $d$-block elements, where considerable covalency is at play. Inhomogeneous line broadening due to crystalline defects or distortions is present so that individual peaks (zero phonon lines and vibronic lines) are not resolved. The crystal field levels of the ground multiplet $(\mathrm{J}=15 / 2)$ induce an expected broadening on the order of a several hundred of wavenumbers, and are, therefore, not likely to explain the range of the observed transitions, here attributed to vibronic coupling.

Photoluminescence lifetime measurements were made in two regions of the emission centered at $525 \mathrm{~nm}$ and yielded decay time constants of $1.2 \pm 0.3 \mu$ s and $20 \pm 2 \mu$ s (inset of Figure 4). The shorter time constant originated primarily from high-energy emission (500 nm); the longer time constant was attributed to the low-energy peak $(600 \mathrm{~nm})$. These assignments were made based on data obtained using optical band-pass filters, which allowed emission from the two bands to be separated. Because of the spread of vibronic bands, the decay measured at $600 \mathrm{~nm}$ is expected to have contributions from the band originating at $525 \mathrm{~nm}$. However, the decay measured at $525 \mathrm{~nm}$ should not be affected by the band originated at $600 \mathrm{~nm}$. These decays are associated with both the luminescence of $\mathrm{Cf}(\mathrm{III})$ itself and energy transfer to the daughter of ${ }^{249} \mathrm{Cf} \alpha$ decay, ${ }^{245} \mathrm{Cm}$, which decays with a longer life-time than ${ }^{249} \mathrm{Cf}$. The $\mathrm{Cm}(\mathrm{III})$ is also excited by the 365 or $420 \mathrm{~nm}$ light. Cooling the sample to $79 \mathrm{~K}$ results in clear resolution of the two features with the $\mathrm{Cf}(\mathrm{III})$ emission centered at $525 \mathrm{~nm}$ and the $\mathrm{Cm}$ (III) emission centered at $600 \mathrm{~nm}$.

The Cf(III) $\mathrm{J}=5 / 2$ (mainly ${ }^{4} \mathrm{P}_{5 / 2}$ ) level lies $\sim 20,000 \mathrm{~cm}^{-1}$ above the ground state, which corresponds to $\sim 500 \mathrm{~nm}$. The next lower energy state is about $2000 \mathrm{~cm}^{-1}$ below this. Thus, $\mathrm{J}=5 / 2$ is an emitting state even at room temperature. $\mathrm{Cf}(\mathrm{III})$ does not have any excited states that could explain an emission near $600 \mathrm{~nm}$. The long life-time of the $600 \mathrm{~nm}$ emission band 
matches with the first excited state of $\mathrm{Cm}(\mathrm{III})$, and is also consistent with a large energy gap since there are no low-lying excited states to quench the $\mathrm{J}=7 / 2$ emission. Additionally, nonradiative relaxation is negligible. Furthermore, the intensity of the variation in the two bands as a function of temperature also confirms this assignment. The $\mathrm{Cm}$ (III) band does not significantly depend on temperature; whereas the $\mathrm{Cf}(\mathrm{III})$ band at $525 \mathrm{~nm}$ is highly temperature sensitive because the energy gap below this emitting level is small. At higher temperature, radiative relaxation is quenched by thermal (phonon) relaxation. Much of the increase in the $\mathrm{Cm}$ (III) emission intensity is due to energy transfer from $\mathrm{Cf}(\mathrm{III})$. Temperature has little influence on the multi-phonon progressions of vibronic transitions, which appear in both emission and absorption spectra. Low temperature only eliminates the hot bands arising from the occupied states above the ground state or the emitting states. Perhaps the most important feature of this is that when $\mathrm{Cm}$ (III) is placed in a coordination environment created by $\mathrm{Cf}(\mathrm{III})$, strong vibronic coupling is observed. The electronic spectroscopy of $\mathrm{Cm}_{2}\left[\mathrm{~B}_{14} \mathrm{O}_{20}(\mathrm{OH})_{7}\left(\mathrm{H}_{2} \mathrm{O}\right)_{2} \mathrm{Cl}\right]$, where $\mathrm{Cm}(\mathrm{III})$ is in a very different coordination environment than when it is doped into $\mathrm{Cf}\left[\mathrm{B}_{6} \mathrm{O}_{8}(\mathrm{OH})_{5}\right]$, lacks these attributes. ${ }^{10}$

Prior electronic structure calculations on $\mathrm{Pu}(\mathrm{III}), \mathrm{Am}(\mathrm{III})$, and $\mathrm{Cm}(\mathrm{III})$ borates revealed overlap between the $6 p$ and $6 d$ orbitals of $\mathrm{Pu}(\mathrm{III}), \mathrm{Am}$ (III), and $\mathrm{Cm}$ (III) with the $2 p$ orbitals of the coordinated borate oxygen atoms. ${ }^{10}$ The overlap only occurs at the base sites of the metal coordination environments and is exclusively to oxygen atoms of $\mathrm{BO}_{4}$ units, not $\mathrm{BO}_{3}$. All sites around the $\mathrm{Cf}(\mathrm{III})$ center in $\mathrm{Cf}\left[\mathrm{B}_{6} \mathrm{O}_{8}(\mathrm{OH})_{5}\right]$ are occupied by either $\mathrm{BO}_{4}$, or at two sites by both $\mathrm{BO}_{3}$ and $\mathrm{BO}_{4}$ via $\mu_{3}$-oxygen atoms. Given the very large charge density of the $\left[\mathrm{BO}_{4}\right]^{5-}$ anions, the coordination environment is providing considerable electron density to the $\mathrm{Cf}(\mathrm{III})$ center creating electronic behavior that has not been observed before for $\mathrm{Cf}(\mathrm{III})$ and is quite unusual for $f$-elements in general.

In order to better understand the bonding, quantum chemical calculations were performed using density functional theory (DFT) on a finite cluster, with the PBE, ${ }^{20} \mathrm{PBE} 0,{ }^{21} \mathrm{~B} 3 \mathrm{LYP}$, and PW91 exchange-correlation functionals. The cluster was designed to describe accurately the first and second coordination sphere of the $\mathrm{Cf}(\mathrm{III})$ ions, resulting in an accurate description of the $\mathrm{Cf}-\mathrm{O}$ bonds. As indicated by the calculated charges, both Mulliken and Natural Bond Orbitals (NBO), provided in Supplementary Table 3, the effective charge on the Cf ions is far from the 
formal $+\mathrm{III}$ at the DFT level. The Mulliken charges range from 1.5 to $1.85 \mathrm{e}$, and the NBO charges range from 1.70 to 1.85 e. Clearly, the charges are not +3 as expected for a fully ionic structure and do not strongly depend on whether a pure generalize gradient approximation (GGA) or hybrid functional is used. Further analysis of the electron populations shows that much of the additional charge resides in the $6 d$ orbitals with $\sim 0.7 \mathrm{e}$. There is about $0.3 \mathrm{e}$ in the $7 p$ and $\sim 0.1$ to $\sim 0.25$ e additional population in the $5 f$ orbitals.

Given the number of interacting oxygens (8) in the first shell of the ligands, there is not much of an interaction for a given oxygen atom with the $5 f$ orbitals as shown in Supplementary Fig. 5. The NBO population for the $7 s(0.08 \mathrm{e})$ is somewhat less than the Mulliken population on the $7 s$. As a check of the potential for issues with spin contamination with the $5 f^{9} \mathrm{Cf}$ (III) complex, we performed the same calculations with the high-spin $5 f^{7} \mathrm{Cm}$ (III), which will not have this issue. The results, as shown in the Supplementary Information, are essentially the same between $\mathrm{Cf}$ and $\mathrm{Cm}$ demonstrating that this is not an issue. We also checked to see if the removal of protons to create a more negative ligand about the $\mathrm{Cf}$ (and $\mathrm{Cm}$ ) changed the effective orbital interactions at the actinide, and they did not. Overall, the predicted charges show that there is a substantial charge donation from the borate oxygen ligands to the $\mathrm{Cf}$, with about half of this extra charge into the $6 d$.

The topological analysis of the electron localization function (ELF) ${ }^{22,23}$ shows electrondonation from the eight coordinated $\mathrm{O}$ atoms to the $\mathrm{Cf}$. About 1 to 4 bonding electrons can be found between the Cf atom and each of the coordinated O atoms (see Supplementary Table 5), consistent with the charge results. As several molecular orbitals can contribute to the same covalent basin, the analogy between the ELF approach and the notion of bonding in terms of molecular orbitals is not direct.

In order to better understand the electronic structure of $\mathrm{Cf}$, the crystal-field splitting of the ground free-ion term $\left({ }^{6} \mathrm{H}\right)$ has been predicted with complete active space self-consistent field (CASSCF) calculations, including either all the high-spin $5 f^{9}$ states (21 sextets) or the states belonging to the ${ }^{6} \mathrm{H}$ of the free-ion (11 states). Supplementary Tables 7 and 8 show that both sets of calculations predict similar results. The lowest 11 states are not degenerate, as expected from symmetry arguments (the cluster belongs to the $C_{2}$ symmetry point group). The total splitting of this term (between the lowest and the highest root) is about $230 \mathrm{meV}\left(\sim 1850 \mathrm{~cm}^{-1}\right)$. We 
conclude that unusually significant crystal-field splitting is present in this system. Thus, the crystal field can also participate in the broadening observed in absorption and emission spectra, and the reduction in the magnetic moment. Due to the high computational cost, the CASSCF calculations do not include basis functions to describe the critical $6 d$ and $7 p$ levels, so the CASSCF cannot be used to examine the amount of covalency. However, the CASSCF calculations do show that there is at least 0.16 e transferred to the $5 f$ orbitals from the ligands consistent with the larger basis set DFT results.

\section{Conclusions}

It is important to note that while $\mathrm{Pu}(\mathrm{III}), \mathrm{Am}(\mathrm{III})$, and $\mathrm{Cm}(\mathrm{III})$ also form covalent bonds with borate, this bonding does not result in substantial changes in electronic properties with respect to the corresponding free ions, e.g. by having a large crystal-field splitting of the ground free-ion term. These effects have not yet been observed with other trivalent actinides, and thus are so far considered specific to this $\mathrm{Cf}(\mathrm{III})$ compound. In a previously reported $\mathrm{Pu}(\mathrm{III})$ structure, the delocalization of the electron density between the trivalent actinide and the borate was quite weak, and the orbital overlap with $\mathrm{Pu}(\mathrm{III})$ did not significantly change the electronic properties of $\mathrm{Pu}(\mathrm{III})$; i.e. the $f-f$ transitions were not broadened and vibronic coupling was absent. Similarly, the significant overlap between the $6 d$ orbital and oxygen $2 p$ orbitals from borate did not alter the $5 f$ electron behavior of $\mathrm{Am}(\mathrm{III})$. On the other hand, $\mathrm{Cm}$ (III) shows the signatures of vibronic coupling in the emission spectrum when placed in the same coordination environment as $\mathrm{Cf}(\mathrm{III})$, demonstrating that the coordination environment can play an important role in the properties of trivalent actinide ions. Quantum mechanical calculations support significant donation of ligand oxygen electron density (from the $\mathrm{O} 2 p$ ) to valence orbitals of $\mathrm{Cf}(\mathrm{III}$ ), notably the $6 d$ followed by the $5 f$ and $7 p$, suggesting the presence of some covalent character in the $\mathrm{Cf}-\mathrm{O}$ bonds. Owing to the number of ligands (8) in the first coordination shell, there is about $0.15 \mathrm{e}$ donated to the $\mathrm{Cf}$ from each ligand. In conclusion, with judicious choice of ligands capable of partial covalent bonding with late actinides, we have obtained a unique $\mathrm{Cf}(\mathrm{III})$ material that is unprecedented in the $f$-block. 


\section{Methods}

\section{Experimental:}

Caution! ${ }^{249} C f\left(t_{1 / 2}=351 \mathrm{y}\right.$; specific activity $\left.=4.1 \mathrm{Ci} / \mathrm{g}\right)$, represent a serious health risk owing to its $\alpha(6.194 \mathrm{MeV})$ and more importantly its $\gamma(0.388 \mathrm{MeV})$ emission, and the emission of its daughters. ${ }^{249} \mathrm{Cf}$ decays to ${ }^{245} \mathrm{Cm}\left(t_{1 / 2}=8,500 \mathrm{y}\right)$ which is a potent $\alpha$-emitter and undergoes spontaneous fission releasing a large flux of neutrons. All studies with californium were conducted in a laboratory dedicated to studies on transuranium elements. This laboratory is equipped with HEPA filtered hoods and negative pressure glove boxes that are ported directly into the hoods. A series of counters continually monitor radiation levels in the laboratory. The laboratory is licensed by the Nuclear Regulatory Commission and the State of Florida. All experiments were carried out with approved safety operating procedures. All free-flowing solids are worked with in glove boxes, and products are only examined when coated with either water or Krytox oil and water.

All work was conducted within a negative pressure glovebox and whenever possible the samples were shielded with lead. The sample used produces $1.7 \mathrm{R} / \mathrm{hr}$ at $40 \mathrm{~mm}$ and therefore represents a serious external hazard that required the experiments to be carefully choreographed to minimize exposure times.

\section{Synthesis:}

$\mathrm{Cf}\left[\mathrm{B}_{6} \mathrm{O}_{8}(\mathrm{OH})_{5}\right]$ was synthesized using ${ }^{249} \mathrm{CfCl}_{3}$ that was used as received from Oak Ridge National Laboratory. $5 \mathrm{mg}(0.01 \mathrm{mmol})$ of ${ }^{249} \mathrm{CfCl}_{3}$ was dissolved in Millipore water $(30 \mu \mathrm{L})$ and then transferred to a PTFE-lined Parr 4749 autoclave with a $10 \mathrm{~mL}$ internal volume. $63 \mathrm{mg}$ (1.0 mmol) of boric acid was added to the droplet containing the dissolved $\mathrm{Cf}(\mathrm{III})$. The mixture was then sealed and heated at $240{ }^{\circ} \mathrm{C}$ for seven days followed by slow cooling to room temperature over a three day period $\left(3^{\circ} \mathrm{C} / \mathrm{hr}\right)$. The furnace for heating the autoclave was also inside the glovebox and surrounded by thick lead sheets. The resulting product was washed with warm water to remove the excess boric acid flux and consisted of pale green microcrystalline clusters (see Supplementary Fig. 1). 


\section{Crystallographic Studies:}

Single crystals of $\mathrm{Cf}\left[\mathrm{B}_{6} \mathrm{O}_{8}(\mathrm{OH})_{5}\right]$ were glued to cryoloops with epoxy and optically aligned on a Bruker D8 Quest X-ray diffractometer using a digital camera. Initial intensity measurements were performed using a I $\mu \mathrm{S}$ X-ray source $(\operatorname{MoK} \alpha, \lambda=0.71073 \AA$ ) with highbrilliance and high-performance focusing multilayer optics. Standard software was used for determination of the unit cells and data collection control. The intensities of reflections of a sphere were collected by a combination of multiple sets of exposures (frames). Each set had a different $\varphi$ angle for the crystal and each exposure covered a range of $0.5^{\circ}$ in $\omega$. A total of 2716 frames were collected with an exposure time of $120 \mathrm{~s}$. The SAINT software was used for data integration including Lorentz and polarization corrections. The structure was solved by direct methods and refined on $\mathrm{F}^{2}$ by full-matrix least squares techniques using the program suite SHELX. Parameters for Cf are not present in the SHELX software and have to be inputted manually. Solutions were checked for missed symmetry using PLATON. ${ }^{24}$

\section{UV-vis-NIR and Photoluminescence Spectroscopy:}

UV-vis-NIR and photoluminescence data were acquired from a cluster of microcrystals using a Craic Technologies microspectrophotometer. Crystals were placed on quartz slides under Krytox oil, and the absorption data were collected from 400 to $800 \mathrm{~nm}$. The exposure time was auto-optimized by the Craic software. Photoluminescence data were acquired using the same microspectrophotometer with excitation wavelengths of $280,365,420$, or $546 \mathrm{~nm}$, an exposure of $5 \mathrm{~s}$, and an aperture size of 103 x $103 \mu \mathrm{m}$ (Figure 4). Temperature control was achieved by using a Linkam temperature control stage. Raman measurements were also attempted, but these were impeded by the self-luminescence.

\section{Life-time Measurements:}

Time-correlated single-photon counting (TCSPC) photoluminescence measurements were carried out using a femtosecond laser system. A Spectra-Physics Tsunami titanium sapphire oscillator produced pulses that were amplified by a 1-kHz Spitfire regenerative amplifier, producing 800-nm pulses with a temporal duration of $100 \mathrm{fs}$. This fundamental output was frequency doubled, producing 400-nm light that was attenuated to sub-microjoule pulse energies for TCSPC measurements. Visible photoluminescence was isolated from laser light using several dichroic beam splitters. The isolated photoluminescence was directed to an 
avalanche photodiode (id Quantique, id-100-20-ULN), and TCSPC data was acquired using a 16-channel photon correlator (Becker Hickl). The high- and low-energy regions of PL were separated using band-pass filters. The temporal dynamic range of the time-domain measurements extended from sub-picosecond to millisecond time scales. Photoluminescence lifetimes were fit using in-house software.

\section{Magnetic Measurements:}

Magnetic measurements were performed on a polycrystalline sample containing $750 \mu \mathrm{g}$ of ${ }^{249} \mathrm{Cf}$ that was placed in a tightly closed PTFE sample holder, with a Quantum Design SQUID magnetometer MPMS-XL. DC magnetic susceptibility measurements were carried out in an applied field of $0.100 \mathrm{~T}$ in the $1.8-380 \mathrm{~K}$ temperature range. Field-dependent magnetization was recorded at $1.8 \mathrm{~K}$ in the magnetic field varying from 0 to $7 \mathrm{~T}$. The data were corrected for the diamagnetic contribution from the sample holder and constituent elements.

\section{Computations:}

While the position of the $\mathrm{Cf}, \mathrm{O}$ and $\mathrm{B}$ atoms of the cluster was taken from the crystallographic structure, the position of the $\mathrm{H}$ atoms (initially present in the crystallographic structure or added to "neutralize" the cluster) were optimized with the Perdew-Burke-Ernzerhof (PBE) functional ${ }^{23}$, using the TURBOMOLE program package. ${ }^{25}$ During this optimization, a $C_{2}$ symmetry point group was imposed. One should note that the $C_{2}$ symmetry arises from the first, second and third coordination spheres, and hence that the imposed symmetry constraint only affects the added protons. All-electron def-TZVP basis sets ${ }^{26}$ were used for all the atoms, except the $\mathrm{Cf}$ atom, which was treated using a 60-electron core quasi-relativistic pseudopotential. ${ }^{27} \mathrm{~A}$ sextet spin state was considered for the optimization of the $\mathrm{H}$ atoms. The cluster employed in our calculations is illustrated in Supplementary Figs. 2, 3, and 5. A single point unrestricted DFT calculation was then performed at this geometry with the PBE0 functional. ${ }^{28}$ Test calculations showed that the lowest energy quartet and doublet spin configurations lie about 30 and $50 \mathrm{kcal} / \mathrm{mol}$ above the lowest sextet spin state, respectively, and thus only the electronic structure of the ground sextet state is considered in the subsequent population analysis. Restricted open-shell Kohn-Sham (KS) DFT single point calculations were performed with allelectron def-TZVP basis sets ${ }^{26}$ on $\mathrm{H}, \mathrm{B}$ and $\mathrm{O}$ atoms and Stuttgart ECP60MWB contracted 
pseudopotential basis set ${ }^{27,29}$ on Cf, with both the PBE and PBE0 functionals, using the Gaussian 09 program package. ${ }^{30}$

Mulliken charge and spin populations were computed and for the B3LYP and PW91 functionals, Natural Bond Orbital (NBO) populations ${ }^{31,32}$ were also calculated. An electron localization function analysis was performed. ${ }^{23,26}$ The ELF and electron density values were computed on a grid with the DGrid program, v. 4.6. ${ }^{33}$ The topological analysis of the ELF allows discussing the nature of chemical bonds. ${ }^{34}$ The number of bonding electrons for each $\mathrm{Cf}-\mathrm{O}$ pair is presented in Supplementary Table 6. Multiconfigurational wave function based calculations were performed with the complete active space self-consistent field (CASSCF) method ${ }^{22}$ with the Molcas program. ${ }^{35}$ The minimal ANO-DK3 basis set ${ }^{36}$ is used for all atoms. The DouglassKroll-Hess Hamiltonian ${ }^{37,38}$ is used to explicitly account for scalar relativistic effects.

Acknowledgments: We are grateful for support provided by the Chemical Sciences, Geosciences, and Biosciences Division, Office of Basic Energy Sciences, Office of Science, Heavy Elements Chemistry Program, U.S. Department of Energy, under Grants DE-SC0002215, DE-FG02-13ER16414, DE-SC002183 (NP, RM, and LG), and DEAC02-06CH11357 (DAD, GL, and LS), and for support from the National Science Foundation CAREER award DMR-0955353 (MS). Collaborative work with our German counterparts is supported via the Helmholtz Association, Grant Number: VH-NG-815. The ${ }^{249} \mathrm{Cf}$ was provided to Florida State University via the Isotope Development and Production for Research and Applications Program through the Radiochemical Engineering and Development Center at Oak Ridge National Laboratory and was purchased via the Gregory R. Choppin Chair Endowment.

\section{Author Contributions:}

MJP and TEA-S conceived, designed, and carried out the synthetic and crystallographic experiments. RM, NP, LG, EG, and DAD designed and carried out the quantum mechanical study. JTS, JNC, and TGP carried out low temperature spectroscopic experiments. EVA and WD were involved in the crystallographic analysis. GL analyzed all spectroscopic experiments. MS designed and carried out the magnetic experiments and, along with SS and LS, analyzed the magnetic data. TBG and KLK carried out the photoluminescence lifetime measurements. SMVC prepared and manipulated the original stock of ${ }^{249} \mathrm{Cf}$ at ORNL. All authors discussed and co-wrote the manuscript. 


\section{References:}

1. Sykora, R. E., Assefa, Z., Haire, R. G. \& Albrecht-Schmitt, T. E. The first structural determination of a trivalent californium compound with oxygen coordination. Inorg. Chem. 45, 475-477 (2006).

2. Burns, J. H. Peterson, J. R. \& Baybarz, R. D. Hexagonal and orthorhombic crystal structures of californium trichloride. J. Inorg. Nucl. Chem. 35, 1171-1177 (1973).

3. Laubereau, P. G. \& Burns, J. H. Microchemical preparation of tricyclopentadienyl compounds of berkelium, californium, and some lanthanide elements. Inorg. Chem. 9, 1091-1095 (1970).

4. Galbis, E. et al. Solving the hydration structure of the heaviest actinide aqua ion known: The californium(III) case. Angew. Chem. Int. Ed. 49, 3811-3815 (2010).

5. Lindqvist-Reis, P. et al. The structures and optical spectra of hydrated transplutonium ions in the solid state and solution. Angew. Chem. Int. Ed. 46, 919-922 (2007).

6. Apostolidis, C. et al. $\left[\mathrm{An}\left(\mathrm{H}_{2} \mathrm{O}\right)_{9}\right]\left[\mathrm{CF}_{3} \mathrm{SO}_{3}\right]_{3}(\mathrm{An}=\mathrm{U}-\mathrm{Cm}, \mathrm{Cf})$ : Exploring their stability, structural chemistry, and magnetic behavior by experiment and theory. Angew. Chem. Int. Ed. 49, 6343-6347 (2010).

7. Skanthakumar, S. Antonio, M. R., Wilson, R. E. \& Soderholm, L. The curium aqua ion. Inorg. Chem. 46, 3485-3491 (2007).

8. Kaltsoyannis, N. Does covalency increase or decrease across the actinide series? Implications for minor actinide partitioning. Inorg. Chem. 52, 3407-3413 (2013).

9. Neidig, M. L., Clark, D. L. \& Martin, R. L. Covalency in f-element complexes. Coord. Chem. Rev. 257, 394-406 (2013).

10. Polinski, M. J. et al. Differentiating between trivalent lanthanides and actinides. J. Am. Chem. Soc. 134, 10682-10692 (2012).

11. Ruiz-Martínez, A., Casanova, D. \& Alverz, S. Polyhedral structures with an odd number of vertices: Nine-coordinate metal compounds. Chem. Eur. J. 14, 1291-1303 (2008).

12. Ruiz-Martínez, A. \& Alverz, S. Stereochemistry of compounds with coordination number ten. Chem. Eur. J. 15, 7470-7480 (2009).

13. Li, L. et al. Synthesis of rare earth polyborates using molten boric acid as a flux. Chem. Mater. 14, 4963-4968 (2002).

14. Castro-Rodriguez, I. et al. Uranium tri-aryloxide derivatives supported by triazacyclononane: Engendering a reactive uranium(III) center with a single pocket for reactivity. J. Am. Chem. Soc. 125, 4565-4571 (2003) 
15. Skanthakumar, S., Soderholm, L. \& Movshovich, R. Magnetic properties of Dy in $\mathrm{Pb}_{2} \mathrm{Sr}_{2} \mathrm{DyCu}_{3} \mathrm{O}_{8}$. J. Alloys Compd. 303, 298-302 (2000).

16. Staub, U. et al. Valence determination as a function of doping in $\mathrm{PrBa}_{2} \mathrm{Cu}_{3} \mathrm{O}_{7-\delta}$. Phys. Rev. B. 61, 1548 (2000).

17. Fields, P. R., Wybourne, B. G. \& Carnall, W. T. The electronic energy levels of the heavy actinides $\mathrm{Bk}^{3+}\left(5 \mathrm{f}^{8}\right), \mathrm{Cf}^{3+}\left(5 \mathrm{f}^{9}\right), \mathrm{Es}^{3+}\left(5 \mathrm{f}^{10}\right)$, and $\mathrm{Fm}^{3+}\left(5 \mathrm{f}^{11}\right)$. Argonne National Laboratory AEC Research and Development Report (U.S. Atomic Energy Commission), ANL-6911 (1964).

18. Campos, A. F., Meijerink, A., de Mellow Donegá, C. \& Malta, O. L. A theoretical calculation of vibronic coupling strength: the trend in the lanthanide ion series and the hostlattice dependence. J. Phys. Chem. Solids. 61, 1489-1498 (2000).

19. Legendziewicz, J. Spectroscopy and structure of selected lanthanide polymeric and monomeric systems. J. Alloys Compd. 300, 71-87 (2000).

20. Perdew, J. P., Ernzerhof, M. \& Burke, K. Rationale for mixing exact exchange with density functional approximations. J. Chem. Phys. 119, $9982-9985$ (1996).

21. Perdew, J. P., Burke, V. \& Ernzerhof, M. Generalized gradient approximation made simple. Phys. Rev. Lett. 77, 3865-3868 (1996).

22. Roos, B. O., Taylor, P. R., \& Siegbahn, P. E. M. A complete active space SCF method (CASSCF) using a density matrix formulated super-CI approach, Chem. Phys., 48, 157-173 (1980).

23. Kohout, M. \& Savin, A. Atomic shell structure and electron numbers, Int. J. Quant. Chem. 60, 875-882 (1996).

24. Spek, A. L. Single-crystal structure validation with the program PLATON. J. Appl. Cryst. 36, 7-13 (2003).

25. TURBOMOLE v6.4 2012, a development of the University of Karlsruhe and Forschungszentrum Karlsruhe GmbH, 1989-2007, TURBOMOLE GmbH, since 2007, available from http://www.turbomole.com.

26. Becke, A. D. \& Edgecombe, K. E. A simple measure of electron localization in atomic and molecular systems. J. Chem. Phys. 92, 5397-5403 (1990).27. Schäfer, A., Huber, C. \& Ahlrichs, R. Fully optimized contracted Gaussian basis sets of triple zeta valence quality for atoms Li to Kr. J. Chem. Phys. 100, 5829-5835 (1994).

28. Cao, X. \& Dolg, M. Segmented contraction scheme for small-core actinide pseudopotential basis sets. J. Molec. Struct. (THEOCHEM), 673, 203-209 (2004).

29. Cao, X., Dolg, M. \& Stoll, H. Valence basis sets for relativistic energy-consistent small-core actinide pseudopotentials. J. Chem. Phys. 118, 487-497 (2003). 
30. Frisch, M. J. et al. Gaussian 09, Revision C.01, Gaussian, Inc., Wallingford, CT, 2011.

31. Reed, A. E.; Curtiss, L. A.; Weinhold, F., Intermolecular interactions from a natural bond orbital, donor-acceptor viewpoint. Chem. Rev. 88, 899-926 (1988).

32. Weinhold, F.; Landis, C. R., Valency and Bonding. Cambridge University Press: 2005.

33. Kohout, M. DGrid, version 4.6, Radebeul, 2011.

34. Silvi, B. \& Savin, A. Classification of chemical bonds based on topological analysis of electron localization functions. Nature, 371, 683-686 (1994).

35. Aquilante, F. et al. MOLCAS 7: The next generation. J. Comput. Chem. 31, 224-247 (2010).

36. Tsuchiya, T., Abe, M., Nakajima, T. \& Hirao, K. Accurate relativistic Gaussian basis sets for $\mathrm{H}$ through $\mathrm{Lr}$ determined by atomic self-consistent field calculations with the third-order Douglas-Kroll approximation. J. Chem. Phys. 115, 4463 (2001).

37. Douglas, N. \& Kroll, N. M. Quantum electrodynamical corrections to fine-structure of helium. Ann. Phys. 82, 89-155 (1974).

38. Hess, B. A. Relativistic electronic-structure calculations employing a 2-component no-pair formalism with external-field projection operators. Phys. Rev. A 33, 3742-3748 (1986).

39. Becke, A. D., Density-functional thermochemistry. III. The role of exact exchange. J. Chem. Phys. 98, 5648-5652 (1993).

40. Lee, C.; Yang, W.; Parr, R. G., Development of the Colle-Salvetti correlation-energy formula into a functional of the electron density. Phys. Rev. B: Condens. Matter. 37, 785-789 (1988).

41. Godbout, N.; Salahub, D. R.; Andzelm, J.; Wimmer, E., Optimization of Gaussian-type basis sets for local spin density functional calculations. Part I. Boron through neon, optimization technique and validation. Can. J. Chem. 70, 560-571 (1992).

42. Perdew, J. P.; Jackson, K. A.; Pederson, M. R.; Singh, D. J.; Fiolhais, C., Atoms, molecules, solids, and surfaces: Applications of the generalized gradient approximation for exchange and correlation. Phys. Rev. B: Condens. Matter. 46, 6671-6687 (1992).

43. Perdew, J. P.; Burke, K.; Ernzerhof, M., Generalized Gradient Approximation Made Simple. Phys. Rev. Lett. 77, 3865-3868 (1996). 
Figure 1: Graphical representations of the fundamental building block of borate units (a), distorted square antiprismatic coordination environment of the $\mathrm{Cf}(\mathrm{III})$ (b), and overall twodimensional sheet structure viewed parallel to the $[a b]$ plane (c) of $\mathrm{Cf}\left[\mathrm{B}_{6} \mathrm{O}_{8}(\mathrm{OH})_{5}\right]$. The $\mathrm{BO}_{3}$ triangles are depicted by the dark green polyhedra, $\mathrm{BO}_{4}$ tetrahedra are depicted by light green polyhedra, and the $\mathrm{CfO}_{8}$ units are depicted by orange polyhedra.

Figure 2: The magnetic susceptibility obtained from a polycrystalline sample of $\mathrm{Cf}\left[\mathrm{B}_{6} \mathrm{O}_{8}(\mathrm{OH})_{5}\right]$ (open circles) compared with the fit (solid line) obtained using a modified Curie-Weiss law. The field dependent magnetization (M), shown in the inset for data obtained at $1.8 \mathrm{~K}$, saturates at low field. The $\mu_{\text {eff }}=6.7(4)$ is significantly less than the expectation value of $10.65 \mu_{\mathrm{B}}$ for the ${ }^{6} H_{15 / 2}$ ground state based on Russell-Saunders coupling.

Figure 3: Room temperature solid-state absorption spectrum of $\mathrm{Cf}\left[\mathrm{B}_{6} \mathrm{O}_{8}(\mathrm{OH})_{5}\right]$ obtained from a cluster of crystals showing $f-f$ transitions that are diagnostic for $\mathrm{Cf}(\mathrm{III})$. The $f-f$ transitions are broader than what are typically observed for other trivalent actinides and lanthanides. Vibronic features are clearly observed to the right of peak at $475 \mathrm{~nm}$. Assignments: $\mathbf{1}-34 \%{ }^{6} \mathrm{~F}_{9 / 2}, 28 \%$ ${ }^{6} \mathrm{H}_{9 / 2}, 16 \%{ }^{4} \mathrm{~F}_{9 / 2}, 11 \%{ }^{2} \mathrm{G}_{9 / 2} ; 2-48 \%{ }^{4} \mathrm{~K}_{17 / 2}, 26 \%{ }^{4} \mathrm{~L}_{17 / 2}, 14 \%{ }^{2} \mathrm{~L}_{17 / 2}, 13 \%{ }^{4} \mathrm{M}_{17 / 2} ; 3-56 \%{ }^{6} \mathrm{~F}_{1 / 2}$, $37 \%{ }^{4} \mathrm{D}_{1 / 2} ; \mathbf{4}-37 \%{ }^{6} \mathrm{~F}_{5 / 2}, 29 \%{ }^{6} \mathrm{H}_{5 / 2}, 13 \%{ }^{4} \mathrm{G}_{5 / 2}, 12 \%{ }^{4} \mathrm{D}_{5 / 2} ; \mathbf{5}-53 \%{ }^{6} \mathrm{H}_{7 / 2}, 23 \%{ }^{4} \mathrm{G}_{7 / 2} ; \mathbf{6}-32 \%$ ${ }^{4} \mathrm{D}_{3 / 2}, 27 \%{ }^{6} \mathrm{~F}_{3 / 2}, 17 \%{ }^{2} \mathrm{P}_{3 / 2} ; 7-51 \%{ }^{6} \mathrm{H}_{9 / 2}, 21 \%{ }^{6} \mathrm{~F}_{9 / 2}, 19 \%{ }^{4} \mathrm{G}_{9 / 2} .{ }^{17}$

Figure 4: Photoluminescence spectra of $\mathrm{Cf}\left[\mathrm{B}_{6} \mathrm{O}_{8}(\mathrm{OH})_{5}\right]$ upon excitation with $420 \mathrm{~nm}$ light as a function of temperature. The emission from $\mathrm{Cf}$ (III) is centered at $525 \mathrm{~nm}$; whereas the emission from the $\mathrm{Cm}$ (III) daughter occurs at $600 \mathrm{~nm}$. Both features indicate substantial vibronic coupling. Inset shows the decay life-times of $1.2 \pm 0.3 \mu$ s for $\mathrm{Cf}(\mathrm{III})$ and $20 \pm 2 \mu$ s for the $\mathrm{Cm}$ (III) daughter. The red and blue traces represent least-squares fits to the decay measurements. 